\title{
RETÓRICA VISUAL Y FORMAS DEL BARRO EN LOS RELIEVES DE MIGUEL PERRIN DE LA CATEDRAL DE SEVILLA
}

\author{
VISUAL RHETORIC AND TERRACOTTA SHAPES IN \\ MIGUEL PERRIN'S RELIEFS FOR SEVILLE CATHEDRAL
}

\author{
Teresa Laguna Paúl \\ Universidad de Sevilla. España \\ ORCID: 0000-0003-3266-5552 \\ teresalaguna@us.es
}

Entre 1519 y 1522, la catedral de Sevilla llevó a cabo la remodelación y terminación de sus portadas norte y este: las puertas del Perdón “vieja”, de la Epifanía y de la Entrada en Jerusalén, cuyos programas escultóricos realizó Miguel Perrin. La investigación interpreta el contexto funcional y litúrgico de estos accesos, el mensaje figurativo y las fuentes visuales de los tres relieves, aportando nueva información de su composición y técnica en barro cocido.

Palabras clave: Miguel Perin o Miguel Perrin; escultura renacentista; escultura en barro cocido; terracota; catedral de Sevilla.

Between 1519 and 1522, the Cathedral of Seville redesigned and finished its Northern and Eastern façades: the "old" Forgiveness gateway, and those of the Epiphany and the Entry into Jerusalem, with relief sculptures by Miguel Perrin. The present research focuses on the functional and liturgical purposes of all three gateways, it studies their messages and artistic sources, and offers new information on their design and the terracotta techniques employed.

Keywords: Miguel Perin or Miguel Perrin; Renaissance sculpture; sculpture in baked clay; terracotta reliefs; Seville Cathedral.

\section{INTRODUCCIÓN}

La personalidad artística del escultor francés Miguel Perrin ha sido depurada en recientes trabajos que dieron luz a ciertas imprecisiones historiográficas relativas a su origen, formación y procedencia desde que Juan Agustín Ceán Bermúdez

${ }^{*}$ Laboratorio de Arte (HUM-210). Investigación inserta en el proyecto El patronazgo artístico en el Reino de Castilla y León (1230-1500). Obispos y catedrales II (HAR201788045-P). 
confundiera al "maestre Miguel" de la documentación de la catedral de Sevilla con un inexistente Miguel Florentín en los trabajos de la puerta del Perdón de esta seo y, afortunadamente, José Hernández Díaz identificara a dicho maestro con Miguel Perin o Perrin en $1932^{1}$.

Miguel Perrin es un maestro de técnica depurada, especializado en esculturas monumentales de barro cocido, en el que se observa una formación, previsiblemente, bajo la influencia de artistas italianos activos en las regiones de la Campaña, del valle del Loira o de Borgoña. Con relación a sus orígenes señalé una incierta relación con el escultor del mismo nombre que realizó ciertas obras decorativas de barro cocido para el palacio ducal y la iglesia de Saint-Maxe de Bar-le-Duc (Barrois, Lorena, Francia), no conservadas. En sus esculturas y relieves existen formalismos tomados de Francisco Laurana y del círculo de artistas italianos vinculados con el cardenal Georges de Amboise que, como Jérôme Pacherot y Antonio di Giusto Betti (Juste), le aportarían un conocimiento directo del arte italiano. Algunas obras recuerdan elementos presentes de los primeros trabajos de Felipe de Bigarny en el trasaltar de la catedral de Burgos o

${ }^{1}$ LAGUNA PAUUL, Teresa: "Miguel Perin, en las portadas de la catedral de Sevilla, Maestre Miguel o la fortuna artística de un imaginero de barro", en ÁLVAREZ MÁRQUEZ, María del Carmen y ROMERO TALLAFIGO, Manuel (coords.): Los archivos de la Iglesia de Sevilla. Homenaje al archivero Pedro Rubio Merino. Córdoba, 2006, pp. 723751; LAGUNA PAÚL, Teresa: "Miguel Perrin, imaginero de barro al servicio de la Catedral de Sevilla", en GÓMEZ PIÑOL, Emilio (coord.): Nuevas perspectivas críticas sobre la historia de la escultura sevillana. Sevilla, 2007, pp. 81-106; LAGUNA PAÚL, Teresa: "Llegada y primeras obras de Miguel Perrin en la catedral de Sevilla: el programa escultórico de la reconstrucción del cimborrio de Rodrigo Gil de Hontañón", Laboratorio de Arte, 24, 2012, pp. 137-162; LAGUNA PAÚL, Teresa: "Cultura visual y promoción artística del escultor Miguel Perrin en la catedral de Sevilla (1517-1552)", en LUGAND, J. (ed.): Les échanges artistiques entre la France et l'Espagne (XVe-fin XIXe siècles). Perpignan, 2012, pp. 143-163; CIRUJANO, Concha y LAGUNA, Teresa: "Aproximación técnica a las esculturas renacentistas en barro cocido de Miguel Perrin", Laboratorio de Arte, 22, 2010, pp. 33-50; CIRUJANO, Concha y LAGUNA, Teresa: "Ôeuvre et technique de Miguel Perrin, sculpteur français a Sevilla", en BOUDON-MACHUEL, M. (coord.): La sculpture française du XVIe siècle. Etudes et recherches. París, 2011, pp. 150-165; MONTERROSO MONTERO, Juan Manuel: "Tramas y recursos compositivos: nuevos datos para la apreciación de «La lamentación sobre Cristo muerto» de la catedral de Santiago de Compostela”, Ruta ciclo turista del Románico-Internacional, 23, 2005, pp. 202-215; MONTERROSO MONTERO, Juan Manuel: "Un espacio para la puesta en escena y la devoción. La lamentación sobre Cristo muerto y la capilla de Mondragón en la catedral de Santiago de Compostela”, en FERNÁNDEZ CASTIÑEIRAS, E. y MONTERROSO MONTERO, J. M.: Santiago, ciudad de encuentros y presencias. Santiago, 2012, pp. 111124; y GARCÍA NISTAL, Joaquín: "Miguel Perin en la escultura del Renacimiento español. La Virgen del Oratorio de la Catedral de León", De Arte. Anuario del Departamento de Historia y Teoría del Arte, 21, 2009, pp. 69-80. 
de Copin de Holanda en el retablo de Toledo, que pueden obedecer a modelos o fuentes comunes ${ }^{2}$.

Los trabajos de Miguel Perrin constituyeron un puente escultórico, una alternativa estética y técnica adecuada y moderna, a las necesidades de la catedral de Sevilla donde en las primeras décadas del siglo XVI convivieron los últimos encargos tardogóticos con los primeros renacentistas; la ampliación de la capilla de la Antigua con la presencia de Domenico Fancelli en 1511 para instalar el sepulcro encargado por Íñigo López de Mendoza y las obras vinculadas con la finalización de la obra gótica entre las que estaba su retablo mayor y las esculturas monumentales en barro cocido encargadas para los hastiales interiores del crucero y cimborrio, cerrado en 1506 y desplomado el 28 de diciembre de 1511. En este período la ciudad se transformó, poco a poco, en una urbe cosmopolita con una activa vida cultural y económica, donde la Iglesia de Sevilla tuvo un protagonismo destacado y emprendió reformas importantes e impulsadas por los arzobispos Diego Hurtado de Mendoza y Diego de Deza (1512) ${ }^{3}$.

$\mathrm{Su}$ presencia en Sevilla se inscribe en el contexto de los trabajos del nuevo cimborrio de su catedral y del panorama artístico del 1500 en esta ciudad donde el intercambio artístico, la importación de obras y una intensa circulación de modelos fue determinante en la renovación de los arquetipos nórdicos y en la normalización de los romanos o clasicistas ${ }^{4}$. Cuando las nuevas fórmulas renacentistas llegaron a Sevilla se constata una presencia de artistas franceses e italianos que colaboraron con los talleres locales como, por ejemplo, el imaginero francés Claudio de la Cruz, quien trabajó en el taller de Niculoso Pisano y le hizo un retrato en barro cocido en 1510, lamentablemente no conservado. Estos talleres atendieron las demandas de la clientela laica y eclesiástica de Andalucía occidental, llevaron

${ }^{2}$ LAGUNA PAÚL, Teresa: "Llegada y primeras obras de Miguel Perrin en la catedral de Sevilla: el programa escultórico de la reconstrucción del cimborrio de Rodrigo Gil de Hontañón", Laboratorio de Arte, 24, 2012, pp. 140-141 y 146.

3 LLEÓ CAÑAL, Vicente: Nueva Roma: mitología y humanismo en el Renacimiento sevillano. Sevilla, 1979, pp. 9-24 y ss.; SÁNCHEZ HERRERO, José: "La Sevilla del Renacimiento (1474-1581)", en SÁNCHEZ HERRERO (coord.): Historia de las diócesis españolas 10. Iglesias de Sevilla, Huelva, Jerez y Cádiz y Ceuta. Madrid, 2002, pp. 131-185; y LAGUNA PAÚL, Teresa: "Miguel Perin, en las portadas...", op. cit., pp. 735-736.

${ }^{4}$ CHECA CREMADES, Fernando: Pintura y escultura del Renacimiento en España (1450-1600). Madrid, 1983, pp. 17-175; MARÍAS FRANCO, Fernando: El largo siglo XVI. Madrid, 1989, pp. 33-340; y REDONDO CANTERA, M. ${ }^{a}$ José: "La aportación transpirenaica a la escultura del Renacimiento en la Península Ibérica: Paralelismos e influencias", en P. Flor y T. Vale (coord.): A escultura em Portugal da Idade Media ao inicio da Idade Contemporánea. Historia y Patrimonio. Lisboa, 2011, pp. 141-162. 
a cabo obras para el floreciente comercio artístico con América y también con el reino de Portugal 5 .

La reconstrucción del cimborrio, entre 1512 y 1517, constituyó una etapa capital en las decisiones y encargos artísticos realizados por el cabildo y su arzobispo fray Diego de Deza para la capilla mayor de la catedral. Los daños producidos por el desplome arruinaron el cierre del crucero de Simón de Colonia y redujeron a cascotes la escultura instalada de Pedro Millán (1504-1507), su hijo Juan Pérez (1509-1511) y Jorge Fernández (1510-1511). Durante estos años, la catedral solicitó informes y promovió varias reuniones técnicas con reconocidos arquitectos hasta que, en junio de 1515, aprobó definitivamente las trazas del nuevo cimborrio proyectado por Juan Gil de Hontañón que, con la supervisión del aparejador Gonzalo de Rozas, terminaron en su fase constructiva el 16 de diciembre de $1517^{6}$. Los miembros humanistas del cabildo que fueron testigos privilegiados de la terminación oficial de la obra gótica, alterada por el indicado desastre de 1511, acordaron mes y medio antes de cerrar esta reconstrucción conciliar las formas de su arquitectura tardogótica con un programa figurativo de carácter moderno e imagen más italiana. El 18 de noviembre de 1517, nueve días más tarde de tomar oficialmente esta decisión, había llegado ya a Sevilla "maestre Miguel”, un imaginero francófono dispuesto a iniciar la escultura monumental del nuevo cimborrio de la Magna Hispalense; un artista en plena madurez artística, que tendría contactos con otros entalladores y escultores de origen francés o flamenco establecidos en la península Ibérica y contaba con el beneplácito del arquitecto, del aparejador y del clero. Los dos años invertidos en esta obra del maestro cántabro habrían permitido buscar e indagar respecto al escultor adecuado a las necesidades del capítulo hispalense, establecer sus condiciones laborales y los requisitos

${ }^{5}$ GESTOSO Y PÉREZ, José: Ensayo de un diccionario de los artífices que florecieron en Sevilla desde el siglo XIII al XVIII inclusive. T. I. Sevilla, 1899-1909, p. 394; GESTOSO Y PÉREZ, José: Historia de los barros vidriados sevillanos desde sus orígenes hasta nuestros días. Sevilla, 1903, pp. 172-174; ANGULO ÍÑIGUEZ, Diego: "Dos Menas en México. Esculturas sevillanas", Archivo Español de Arte y Arqueología, 11/31, 1931, p. 151; GALLOPINI, Laura: "Alcuni documenti su Francisco Niculoso Pisano", en D’ARIENZO, L. (coord): Sardegna, Mediterraneo e Atlantico tra medioevo ed età moderna. Studi storici in memoria di Alberto Boscolo. Vol. III. Roma, 1993, pp. 305-306; y PLEGUEZUELO HERNÁNDEZ, Alfonso: "Niculoso Pisano y Portugal. Nuevos datos y algunas hipótesis", en QUILES, Fernando (coord.): Sevilla Lusa. La nación portuguesa en el Reino de Sevilla en tiempos del Barroco. Congreso Internacional (Sevilla 5-7 junio 2017). Sevilla, 2018, pp. 170-183.

6 ALONSO RUIZ, Begoña: "El cimborrio de la Magna Hispalense", en HUERTA FERNÁNDEZ, S. (coord.): Actas del IV Congreso Nacional de Historia de la construcción. Vol. I. Madrid, 2005, pp. 21-33; e IBÁÑEZ FERNÁNDEZ, Javier y ALONSO RUIZ, Begoña: "El cimborrio en la arquitectura española de la Edad Media a la Edad Moderna", Artigrama, 31, 2016, pp. 129-130 y 156-162. 
formulados por el arquitecto y el aparejador, para calibrar las cargas de la imaginería e impedir problemas derivados por el sobrepeso. Estas circunstancias, las redes de información eclesiástica y los contactos de otros técnicos convocados hacen pensar que Miguel Perrin se encontraba en la península Ibérica antes de 1517 y, quizás, formara parte de algún taller vinculado a las obras de Juan Gil de Hontañón, Juan de Álava o, incluso, de Enrique Egas. Tampoco puede olvidarse la presencia de artistas como Jean Jacques llegado desde Galicia para realizar las vidrieras de la capilla mayor y de escultores franceses en Santiago o en Burgos, con talleres regentados por Nicolás de Chanterenne o Felipe de Bigarny entre otros, con los que tendría alguna relación o con las fábricas ligadas a estos arquitectos ${ }^{7}$.

El comienzo de sus trabajos tuvo algunas incidencias sin repercusión en los plazos de entrega del apostolado compuesto por diez y seis esculturas en barro cocido de unos $160 \mathrm{~cm}$ de alto que, instaladas a 30 metros altura en las hornacinas laterales de las paredes del crucero a finales de la primavera de 1519, recibieron una terminación cromática abonada al pintor Andrés de Covarrubias. Este encargo satisfizo las expectativas del cabildo y, antes de concluirlo, le encomendó las esculturas de San Pedro y San Pablo para los estribos de la puerta del Perdón "vieja", la que comunica directamente el patio de los Naranjos con la calle Alemanes. La monumentalidad de estas figuras de 225 x $76 / 83 \mathrm{~cm}$, terminadas en abril de 1519, acaparó el interés de todos los investigadores por su problemática técnica y carácter italiano, aunque sus volúmenes y modelado responden a los mismos modelos del cimborrio. La composición plástica de todos estos es equiparable con otras esculturas realizadas por artistas activos en la Francia septentrional, en la Turena y valle del Loira desde finales del siglo XV y, especialmente, con el apostolado de barro cocido y policromado encargado por el cardenal Georges de Amboise a Antonio di Giusto Betti (Antoine Juste) para su capilla del castillo de Gaillon (Alta Normandía, Francia) en 1508-1509.

\section{RETÓRICA VISUAL DE LA PUERTA DEL PERDÓN 'VIEJA' Y ACCESOS ORIENTALES DE LA CATEDRAL DE SEVILLA}

El encargo de estos últimos apóstoles responde a una clara intención del cabildo por continuar el programa iconográfico de los atrios y puertas de la catedral,

${ }^{7}$ LAGUNA PAÚL, Teresa: "Miguel Perrin en las portadas...", op. cit. pp. 736-738; LAGUNA PAÚL, Teresa: "Llegada y primeras obras...", op. cit., pp. 142-145; LAGUNA PAÚL, Teresa: "Cultura visual y promoción...", op. cit., pp. 147-148; y NIETO ALCAIDE, Víctor: Las vidrieras de la catedral de Sevilla. Madrid, 1969, pp. 77-84.

${ }^{8}$ CRÉPÌN-LEBLOND, Thierry: "La décor peint et sculpté de la Chapelle de Gaillon”, en CREPIN-LEBLOND y TABURET-DELAHAYE: L'Art des frères Amboise. Les chapelles de l'hôtel de Cluny et du château de Gaillón. París, 2007, pp. 102-105; y LAGUNA PAÚL, Teresa: "Llegada y primeras obras...", op. cit., pp. 143-149. 
paralizado desde la terminación de las puertas del Baptisterio y del Nacimiento de la fachada occidental. La pérdida de los libros de las reuniones capitulares celebradas entre 1519 y 1524 impide establecer la fecha precisa en que acordaron llevar a cabo este gran proyecto que, además, presenta una evidente relación con la terminación definitiva de la catedral gótica y la necesaria retórica figurativa de sus accesos y circuitos procesionales. Esta empresa integra la escultura y relieves de la puerta del Perdón "vieja", sin funcionalidad litúrgica en la ceremonia de reconciliación pública de penitentes el Jueves Santo por la terminación constructiva y apertura de la "puerta del perdón nueva" de la fachada occidental hacia 1478, y los accesos orientales del templo: la puerta de la Epifanía o de los "palos" inmediata a la torre campanario catedralicia, y la de la Entrada en Jerusalén o de la "campanilla", frente al emplazamiento del consistorio municipal". La contabilidad conservada permitió reconstruir los seis contratos sucesivos que durante cinco años concertaron con maestre Miguel y la programación de las entregas cuyos pagos, parcialmente publicados, ocasionaron cierta incomprensión en su génesis plástica al obviarse los condicionantes impuestos por el marco arquitectónico, sus modelos, su función litúrgica y situación en el contexto urbano ${ }^{10}$.

La iconografía de los tres accesos se adecua a las necesidades litúrgicas y pastorales del cabildo, pero la disposición abierta de la puerta del Perdón "vieja" propició una organización figurativa dominantemente pictórica en su morfología y diseño. El relieve de la Expulsión de los mercaderes con su moldura semeja un gran cuadro de teatro sacro dispuesto sobre un fondo de yeserías mudéjares, flanqueado en los estribos almohades por las esculturas de la Anunciación y los dos apóstoles con volúmenes y movimientos libres en pleno contexto urbano y comercial de la calle Alemanes. En este acceso destaca el mensaje de la encarnación de Cristo, con la transmisión y difusión de la Nueva Ley de quien arrojó del templo a los mercaderes como constante recordatorio para que la Iglesia y los fieles salvaguarden los valores del espacio sagrado frente al urbano convertido en una lonja de contratación, donde los puestos comerciales instalados en las gradas convivían con el bullicio del área comercial al por mayor, y los pregoneros voceaban las posibles transacciones. En las portadas tardogóticas orientales, dispuestas en el interior de los atrios que abrían frente a la sala capitular y al consistorio municipal en el corral de los Olmos, el tránsito del clero y fieles hacia el interior siempre era ordenado, gradual, y sus escenas presentan una distancia tan próxima que, dentro de los tímpanos, semejan una ventana elevada, precedida por los profetas y ángeles encajados dentro de las hornacinas.

${ }^{9}$ LAGUNA PAÚL, Teresa: "Marco arquitectónico y retórica...", op. cit., pp. 32-34 y 39-42.

${ }^{10}$ LAGUNA PAÚL, Teresa: "Miguel Perin en las portadas...”, op. cit., pp. 723-151; LAGUNA PAÚL, Teresa: "Miguel Perrin, imaginero...”, op. cit., pp. 81-106; y LAGUNA PAÚL, Teresa: "Cultura visual y promoción...”, op. cit., 147-154. 
La secuencia cronológica de sus pagos responde a las prácticas de escultura monumental en otros templos y catedrales con trabajos perfectamente definidos por su complejidad que permitió al cabildo controlar el orden de los encargos, evitar demoras y establecer la terminación de cada sector, y al escultor programar el modelado, cocción y montajes con otros encargos de su clientela particular así como adecuar las características del horno a las cochuras de las figuras, relieves y paisajes ${ }^{11}$. Estos compromisos le facilitaron contactos y compromisos con otros miembros del cabildo y de la sociedad sevillana, le permitieron tener una economía saneada y alquilar una casa del cabildo inmediata al postigo de la Antigua con una renta muy favorable desde 1524 hasta $1528^{12}$ (Figura 1).

En la catedral los acuerdos establecieron comenzar los encargos por los dos apóstoles de la puerta del Perdón "vieja" en 1519 y después concentrar en un mismo contrato las figuras de la Anunciación de este mismo acceso, que sustituiría a las pinturas medievales anteriores, con los diez ángeles de las jambas de la puerta inmediata a la torre en los que trabajó durante siete meses y medio antes de realizar los relieves de ambos accesos; los cuatro pagos del tímpano de la Epifanía por 35.000 maravedíes se libraron desde el 6 de julio de 1520 hasta el 17 de diciembre del mismo año, y los 43.250 maravedíes de la Expulsión de los mercaderes del templo desde este último día hasta el finales de agosto del año siguiente. Terminadas completamente ambas portadas concertaron el tímpano de la Entrada en Jerusalén por 25.000 maravedíes, donde invirtió medio año de trabajo, desde noviembre de 1521 hasta agosto de 1522, y después hizo las diez esculturas de sus jambas junto con otras veintiséis destinadas a la nueva empresa del cabildo en el interior del catedral: las paredes exteriores de su capilla mayor donde se despliega un vasto programa iconográfico con figuras en barro cocido $(130-150 \mathrm{~cm})$ cobijadas bajo cincuenta y nueve tabernáculos concluidos, con sus doseletes y peanas, en el verano de 1522 en sincronía con este encargo cuyas esculturas tuvieron un precio medio de 2.601 maravedíes, el mismo importe abonado en 1519-1520 por la Anunciación y los ángeles señalados; en sus entregas agrupó las imágenes por sectores ya que en agosto de 1523 estaban colocadas las diez de

11 LAGUNA PAÚL, Teresa: "Miguel Perrin, imaginero de barro....”, op. cit., pp. 102104; y LAGUNA PAÚL, Teresa: “Cultura visual y promoción artística...”, op. cit., p. 150.

${ }^{12}$ GESTOSO Y PÉREZ, José: Ensayo de un diccionario..., op. cit., vol. III, p. 224; SANCHO CORBACHO, Heliodoro: Arte sevillano de los siglos XVI y XVII. Sevilla, 1931, p. 22; HERNÁNDEZ DÍAZ, José: "Una obra de maestre Miguel en la catedral de Santiago", Archivo Español de Arte y Arqueología, VIII/23, 1932, p. 151; LAGUNA PAÚL, Teresa: "Miguel Perin, en las portadas...”, op. cit., p. 742; y LAGUNA PAÚL, Teresa: "Miguel Perrin, imaginero...", op. cit., pp. 103-104. 
la puerta de la Campanilla y otras tantas del trasaltar frente al arco de la capilla Real, que flanquean a la Virgen del Reposo ${ }^{13}$.

La relación formal entre los apóstoles de la puerta del Perdón y del cimborrio con las terracotas policromadas de Antonio Juste de la capilla de Gaillon también está presente en el modelado y rasgos de la figura de Cristo arrojando a los mercaderes del templo, que reiteró en la Entrada en Jerusalén y en el espectacular Cristo muerto del altar de la capilla de la Piedad o de los Mondragón de la catedral compostelana. El rey Melchor de la portada de la Epifanía y el de barro cocido conservado en la parroquial de Nuestra Señora de Pontoise (Vexin, Francia), adscrito a algún imaginero vinculado al taller de Gaillon, obedecen a modelos comunes realizados por artistas de formación semejante ${ }^{14}$. La fisonomía del rey Gaspar y algunas de los muros exteriores del altar mayor podrían corresponder a retratos sobrepuestos de algún miembro del cabildo, tomados del natural, en los que encontramos filiaciones con bustos de barro cocido contemporáneos. Para sus personajes del antiguo testamento selecciona siempre prototipos con tocados y ropajes exóticos tomados de los grabados de Lucas de Leyden, de las ilustraciones del Liber Chronicarum de H. Schedel (Anton Korberger, Nuremberg, 1493), de las ediciones de los libros de Horas impresos por Ph. Pingouchet, o de las Biblia Pauperum omnipresentes en la figuración de tapices, pinturas, esculturas o esmaltes franceses contemporáneos (Figuras 2, 3 y 4).

Su conocimiento del arte italiano es evidente en el grupo de niños cantores de la Entrada en Jerusalén (1522) inspirados en los de la cantoría de Luca della Robbia para la catedral de Florencia (1431-1438). Sus cabezas y los modelos de sus ángeles muestran fórmulas derivadas de las terracotas vidriadas del mismo taller florentino que, continuadas por su sobrino Andrea (1435-1525) y Benedetto Buglioni (1459-1521), ejercieron amplia influencia en numerosos artistas de la Borgoña, de la Champaña, de las regiones limítrofes y en aquellos cuya actividad profesional les llevó a los distintos reinos de la península Ibérica. Evidencias

${ }^{13}$ LAGUNA PAÚL, Teresa: "Miguel Perin, en las portadas...", op. cit., p. 742; LAGUNA PAÚL, Teresa: "Miguel Perrin, imaginero de barro al servicio...", op. cit., pp. 98100; LAGUNA PAÚL, Teresa: "Cultura visual y promoción...”, op. cit., pp. 154-158; y LAGUNA PAÚL, Teresa; GUERRA LIBRERO, Fernando y RODRÍGUEZ TROBAJO, Eduardo: "Carpinteros y ensambladores en la estructura del retablo mayor de la catedral de Sevilla", en CELESTE GLORIA, A. (coord.): ORetábulo no espaço Ibero-Americano. Lisboa, 2016, pp. 261-270.

${ }^{14}$ ECOLAN, Guillaume: La sculpture de la Renaissance Dans le Vexin français. París, 2005, pp. 106-107; CARON, Sophie: "De la Toscana à la Normandie. Les ateliers de sculpteurs sur le chantier de Gaillon", en CALAME-LEVERT, HERMANT y TOSCANO (coords.): Une Renaissance en Normandie. Le cardinal Georges d'Amboise bibliophile et Mécène. Montreuil, 2017, pp. 71-92; LAGUNA PAÚL, Teresa: "Miguel Perrin imaginero de barro...", op. cit., p. 92; y LAGUNA PAÚL, Teresa: "Cultura visual y promoción...", op. cit., pp. 152-153. 
de una formación, de importaciones de obras de pequeño o mediano formato y de un ambiente cultural común donde hicieron su aprendizaje aquellos imagineros galos que denotan una huella profunda de los escultores italianos activos en Francia desde finales del siglo XV y de los intercambios interregionales derivados de diversas circunstancias históricas ${ }^{15}$ (Figura 6).

En estos tres relieves y en las condiciones del contrato firmado en marzo de 1526 para la realización del altar de la Piedad en la catedral de Santiago de Compostela, dado a conocer por José Hernández Díaz en 1932, existe una estrecha relación entre el tiempo invertido en su realización, su complejidad técnica, sus planos escenográficos e iconografía que analizamos en este homenaje académico al profesor Vicente Lleó Cañal por los aspectos técnicos relativos al desarrollo artístico de Miguel Perrin.

Las escenas de los tímpanos tardogóticos orientales de la catedral de Sevilla conforman la finalización de un programa iconográfico, iniciado en la década de 1460 en la fachada occidental, destinado a exaltar la figura de Cristo y su mensaje de salvación que, difundido por su Iglesia en aras de ejemplificar el camino de salvación, denotan una vinculación con la función litúrgica de cada atrio. El planteamiento doctrinal y la retórica visual establecida para estas puertas de la cabecera encargadas prácticamente seis décadas después que las primeras del hastial de poniente, comprende los temas de la Epifanía (1520) y de la Entrada en Jerusalén (1521-1522) dispuestos frente a los espacios, que entonces ocupaban las instituciones de gobierno: la sala capitular del cabildo catedral y el consistorio de la ciudad (Ayuntamiento). Una expresión de la búsqueda de ciertos equilibrios entre la jurisdicción de la Iglesia y el poder civil imponiendo la preeminencia del mandato eclesiástico en el marco de la catedral. Plásticamente muestran acontecimientos que reconocen el carácter y presencia mesiánica del Señor en la tierra, presentándolo como un emperador o soberano que vino a anunciar su reino y fue aclamado de manera triunfante por el pueblo a las puertas de Jerusalén.

En la puerta de la Epifanía los reyes le reconocen como el Mesías, el Hijo de Dios y el programa ideológico incide en la salvación que con Él vino a este mundo

${ }_{15}$ BLUNT, Anthony: Arte y arquitectura en Francia 1500-1700. Madrid, 1977, pp. 37-45; CHÉDEAU, Catherine: Les arts à Dijon au XVIe siècle: les débuts de la renaissance 1494-1551. Aix-en-Provence, 1999, pp. 129-160, il. 155 y ss.; GABORIT, Jean Rene y BORMAND, Marc: Les Della Robbia. Sculptures en terre cuite émaillée de la Renaissance italienne. París, 2002, pp. 74-137; ZERNER, Henry: Renaissance Art in France. The invention of Classicism. Reed. París, [1996] 2003, pp. 27-42 y 351-379; DIAS, Pedro: Fídias Peregrino. Nicolau Chanterene e a escultura do Renascimento. Coimbra, 1996; y GRILO, Fernando: "Nicolau Canterenne e a influência italiana na escultura do renascimento em Portugal. Fontes e práticas artísticas", en REDONDO CANTERA, María José (coord.): El modelo italiano en las artes plásticas de la península Ibérica durante el Renacimiento. Valladolid, 2004, pp. 393-422. 
donde su Madre constituye una imagen de la Iglesia. Los magos representan la humildad poderosa y sabia postrada ante Jesús para anunciar la redención y, además, manifiestan otros tiempos de revelación o advientos de preparación y praxis cristiana para alcanzar la Gloria; su adoración constituía el centro de la celebración en la que el creyente emula estos primeros testimonios y define la adhesión sumisa de los hombres más poderosos a Dios con el reconocimiento al ser divino recién nacido ${ }^{16}$. En la entrada triunfal en Jerusalén destaca su relación con el calendario litúrgico anual y procesional, para marcar una vía de reflexión y percepción del camino salvífico cristiano al mostrar aspectos de la procesión de palmas del Domingo de Ramos, que discurría por las gradas de la catedral y hacía estación en el corral de los Olmos, donde las obras del templo gótico determinaron llevar a cabo el sermón solemne en este lugar hasta 1532 cuando las constituciones del arzobispo Alonso Manrique lo devolvieron al interior de la catedral, entre los dos coros. La procesión entraba en el templo por esta puerta, frontera al consistorio, mientras los niños de la capilla musical cantaban el "Gloria laus et honor tibi sit, Rex Christe Redemptor", antes del attollite portas y participar en la misa solemne del altar mayor. La presencia de este coro es inusual en la iconografía grabada, esculpida o pintada de la Entrada en Jerusalén aunque en su disposición existan relaciones con obras contemporáneas como, por ejemplo, la escena homóloga del Libro de Horas al uso de Roma de Ph. Pigouchet, impreso por Simon Vostre en 1498, el grabado del maestro alemán L.C.Z. (h. 1480-1505) o el de la Pequeña Pasión de Alberto Durero (h. 1508-1510), en el lienzo del Maestro A. H. realizado hacia 1510 (Lyon, Beaux Arts H648-b), en una tabla atribuida al Maestro del altar de Thuison donde el lugar de los cantores está ocupado por personajes hebreos (Hermitage Inv. ГЭ-5699), o en el relieve del tímpano de la parroquial de Notre Dame de la Neuville sous Corbie fechado hacia 1525-1530 (Somme, Francia) $)^{17}$. Estos cantores conforman aspectos de la retórica visual demandada por el cabildo y conforman un elemento icónico que convierte a la catedral de Sevilla en una imagen alegórica de la Jerusalén celestial, donde los fieles al participar en la entrada procesional de las palmas percibirían componentes inmateriales de la Gloria, alcanzada mediante la salvación (Figura 6).

\section{LA FORMA DEL BARRO EN LOS RELIEVES DE MIGUEL PERRIN DE LA CATEDRAL DE SEVILLA}

Los dos relieves orientales presentan cambios significativos en la organización espacial y en el modelado de la composición escenográfica de cada escena,

16 ALCOY PEDROS, Rosa: Anticipaciones del Paraíso. El donante y la migración del sentido en el arte del occidente medieval. Vitoria, 2017, pp. 109-ss.; y CARDINI, Marco: Los reyes magos. Historia y leyenda. Barcelona, 2001, pp. 141-179.

${ }^{17}$ LAGUNA PAÚL, Teresa: "Miguel Perrin imaginero de barro...”, op. cit., pp. 93-94. 
concebida para quedar enmarcada dentro del tímpano tardogótico, pero desarrollados con soluciones distintas que obedecen, seguramente, a ciertos cambios técnicos documentados a partir de finales del mes de diciembre cuando administrativamente firmaron los acuerdos para la Adoración de los reyes y comenzó el del relieve de la Expulsión de los mercaderes del templo de la puerta del Perdón. El tratamiento del último pudo condicionar la génesis y concepción del relieve de la Entrada en Jerusalén, documentada entre noviembre de 1521 y agosto de 1522 y después del monumental altar de la Lamentación ante el Cristo muerto compostelano, contratado en 1526.

En la Adoración de los magos el relieve del fondo está anclado en la pared y completamente aislado de las cinco figuras de bulto redondo, porque los protagonistas de la acción evangélica están colocados en el primer plano siguiendo la composición habitual en los portales tardogóticos y del primer Renacimiento, caso del tema homólogo en la fachada principal de la catedral de Como. La disposición escénica recuerda el grabado análogo de la Vida de la Virgen de Alberto Durero (h. 1503), del que Perrin seleccionó algunas partes al igual que otros artistas y obras contemporáneas como, por ejemplo, los relieves del jubé de Villemaur-sur-Vanne en la región de Champagne ${ }^{18}$. El diseño y organización general parte de los modelos desarrollados desde mediados del siglo XV cuando, por influencia de la pintura, introdujeron en los fondos de los tímpanos arquitectónicos, en los retablos o en los altares relieves con la cabalgata de los magos que sortean parajes arbóreos y representan edificios alusivos a la ciudad de Jerusalén con elementos propios de las construcciones septentrionales. En el modelado, en los cortes de cocción y en el montaje de este fondo escénico Miguel Perrin estableció dos zonas perfectamente diferenciadas, separadas por una llaga longitudinal sellada con mortero de yeso. En la parte alta, el bajorrelieve de la ciudad amurallada con torres y arquitecturas estereotipadas puede rastrearse en algunas páginas de las ediciones de 1486 y 1490 de la Peregrinatio in Terram Sanctam de Bernard von Breydenbach, conservadas en la catedral de Sevilla ${ }^{19}$. Las ilustraciones de este libro, como indicó Ana Ávila, fueron reiteradamente empleadas por los pintores del primer tercio del siglo XVI para recrear la ciudad santa como un conjunto urbano contemporáneo que carece de los edificios centralizados o de los que conforman la explanada del templo, alusivos a este y omitido en sus páginas ${ }^{20}$ (Figuras 2 y 4 ).

${ }^{18}$ LAGUNA PAÚL, Teresa: "Miguel Perrin en las portadas...”, op. cit., p. 738; y BOUCHERAT, Veronique: L'Art en Champagne à la fin du Moyen Âge. Productions locales et modèles étrangers (v. 1485-v. 1535). Rennes, 2005, pp. 242-244.

19 SEGURA, Antonio; VALLEJO, Pilar y SÁEZ, José Francisco: Catálogo de incunables de la Biblioteca Capitular y Colombina de Sevilla. Sevilla, 1999, nº 232 y 233.

${ }^{20}$ ROSENAU, Helen: Vision of the Temple. The image of the Temple of Jerusalem in Judaísmo anf the christianity. Londres, 1979, p. 71; y ÁVILA PADRÓN, Ana: Imágenes y símbolos en la arquitectura pintada española (1470-1560). Barcelona, 1993, pp. 51-54. 
La cabalgata modelada en medio relieve y cocida en varias planchas, perfectamente encajadas y con sus uniones semiocultas, desarrolla frontalmente volúmenes animados por los jinetes ataviados con armaduras italianas y borgoñotas de tipología milanesa, que portan adargas del armamento hispano y dan una imagen exótica al cortejo. Junto a estos, en la zona derecha, un joven de rasgos africanos, montado sobre un camello, en una metáfora del poder imperial como poder universal, emprende el camino dejando atrás un edificio porticado donde otros personajes secundarios, agrupados en la puerta, observan la marcha de la comitiva vistiendo túnicas, bonetes y mantos de comienzos del siglo XVI; semejan personajes tomados de la vida cotidiana y alguno necesita impertinentes para mejorar su visión. La parte baja del edificio porticado sirve de apoyo al tejado inclinado del cobertizo con sus animales, presente en el grabado de Durero y prácticamente oculto por la escultura de San José que, colocada delante, rompe visualmente el límite del tímpano gótico. En el extremo opuesto un abrupto monte con la ciudad de Belén, precedida de árboles con copas redondeadas y praderas con rebaños, un pastor tañe su flauta en el interior de una cueva escondida detrás de la escultura del rey Baltasar completamente velado a los ojos de los fieles desde el pavimento del atrio. Esta sección reúne elementos figurativos de diversa procedencia y omite la cabalgata por caminos zigzagueantes que Perrin sustituyó por un cortejo de impronta italiana inspirado en relieves de la historia sagrada o, incluso, en triunfos contemporáneos que conocería o recrearía a partir de dibujos o estampas incorporando iconográficamente el joven nubio, la arquitectura porticada del grabado alemán y los montes escarpados con árboles, puertas fortificadas, edificios representativos y domésticos de carácter septentrional de finales del siglo XV, omnipresentes en el retablo de la Crucifixión del Museo de Unterlinden (1522), en obras de Michael Colombe, de Gil de Siloé y Felipe de Bigarny entre otros ${ }^{21}$.

En la Entrada en Jerusalén la composición desarrolla gradual y unitariamente los distintos planos de la acción, combinando el modelado en altorrelieve del primer plano con los volúmenes huecos del segundo ya que, únicamente, San Pedro y el personaje que extiende su manto con su acompañante son figuras completas de bulto redondo. Este tímpano tiene mayor complejidad técnica, una formulación compositiva de considerable modernidad y supone un enriquecimiento en su trayectoria profesional, aunque queden atenuadas por el marco tardogótico.

${ }^{21}$ CHASTEL, André: El mito del renacimiento, 1420-1520. Ginebra, 1969, pp. 661-ss.; LAGUNA PAÚL, Teresa: "Miguel Perrin imaginero de barro...”, op. cit., pp, 93-94; BOUCHERAT, Veronique: L'Art en Champagne..., op. cit., pp. 256-263; CARDINI, Marco: Los reyes magos..., op. cit., p. 146; y FLOR, Pedro: "Imagens da cidade: os fundos de arquitectura na escultura retabular em pedra do renacimiento em Portugal (1500-1550)", Discursos-lengua. Cultura e Sociedade, IIIa serie. Revista do centro de Estudios Historicos Interdisciplinares, 5, 2003, pp. 97-119. 
No obstante, estos cambios de la composición escultórica ya los había desarrollado Perrin en el relieve de la Expulsión de los mercaderes del templo de la puerta del "Perdón vieja", valorada y ponderada siempre por su carácter italianizante desde el siglo XVIII. Comenzada inmediatamente después de cerrar administrativamente el de la Epifanía, este relieve le ocupó ocho meses de trabajo y su intenso dinamismo quedó reforzado por la gruesa moldura clásica que lo enmarca como un cuadro pictórico de 439 x $352 \mathrm{~cm}$, y originariamente tendría pintado el texto del evangelio de San Juan 2,16, dispuesto en el centro del paño mural cubierto de yeserías pintadas en la remodelación de este acceso entre 1518 y $1522^{22}$ (Figuras 1 y 5).

Esta escena vuela, prácticamente, sobre una repisa tallada en la fachada del patio de los Naranjos, en estas gradas de la calle Alemanes donde anunciaban de viva voz las mercancías vendidas en sus puestos y en la frontera alcaicería de la seda; desde esta altura el Señor parece increpar, todavía, a cuantos están ajenos a salvaguardar el legado y función de su casa de oración. Para realizar este relieve de $380 \mathrm{~cm}$ de alto y $300 \mathrm{~cm}$ de longitud, el cabildo encargó un dibujo, una "muestra", al pintor Pedro Hernández, abonada el 28 de noviembre de aquel año, un mes antes que Miguel Perrin concluyera la Adoración de los Reyes de la puerta de los Palos ${ }^{23}$. La situación de este acceso en la trama urbana y la fecha del boceto señalan una clara intención del cabildo por remarcar los modelos renacentistas no solo en este sector, donde ya estaban terminados los dos apóstoles colosales y la Anunciación, sino en las renovaciones en escultura monumental iniciadas en las figuras del nuevo cimborrio.

La muestra del pintor Pedro Hernández de "cuando nuestro señor echó del templo a los cambiadores y a los que vendían" y su materialización en el relieve refleja los caracteres de los colaboradores y escuela de Alejo Fernández, que marcó las directrices de la pintura sevillana del primer tercio del siglo XVI. Pintores preocupados por recrear sus escenas en un ambiente imaginario pero moderno y humanista, mediante las arquitecturas de Bramante grabadas por Prevedari, o las estampas de Alberto Durero, Martín Schongauer, Lucas de Leyden, Israel van Meckenem, Giacomo Caraglio y Marcantonio Raimondi, que, entre otros, les

${ }^{22}$ GESTOSO Y PÉREZ, José: Sevilla monumental..., op. cit., t. II, p. 86; GUERRERO LOVILLO, José: "Los maestros yeseros sevillanos del siglo XVI", Archivo Español de Arte, 28, 1955, pp. 49-50; RECIO MIR, Álvaro: "La reforma y restauración de la Puerta del Perdón de la catedral de Sevilla de 1578-1580", Laboratorio de Arte, 9, 1996, pp. 74-76; y JIMÉNEZ MARTÍN, Alfonso: "La puerta principal de la aljama almohade de Isbiliya”, Al-Qantara, XXXVIII/2, 2017, pp. 296-297.

${ }^{23}$ ACS (Archivo de la catedral de Sevilla), Fábrica 41, año 1520, f. 9v., cit. en GESTOSO Y PÉREZ, José: Ensayo de un diccionario..., op. cit., t. II, p. 86; LAGUNA PAÚL, Teresa: "Miguel Perrin en las portadas...", op. cit., p. 739; y LAGUNA PAÚL, Teresa: "Miguel Perrin imaginero de barro...", op. cit., p. 94. 
proporcionaron los modelos donde inspirarse y, manipulándolos, ambientar las acciones sagradas ${ }^{24}$.

En este modelo o dibujo preparatorio, que sin duda formó parte de las condiciones establecidas en la contratación del relieve, el pintor invirtió algunos elementos del tema homólogo de la serie de la Pequeña Pasión de Alberto Durero (h. 1508). Situó los carneros y animales en el lateral derecho, agolpó a los mercaderes arrollados por el ímpetu del Señor como hiciera Ghiberti en el batiente de la puerta del Paraíso del baptisterio de Florencia (1425-1452), y modificó al mercader caído mirando a Jesús por las dos esculturas exentas del primer plano en posición contraria a sus modelos inspiradores. Como fondo del intenso movimiento y huida de los expulsados del atrio del templo, evocado como una logia italiana con bustos sobresalientes enmarcados por tondos y un nicho clasicista, el altorrelieve agolpa un grupo de cabezas y otros figurantes saliendo por un arco lateral donde no se renunció a mostrar una vista urbana estereotipada y repetida en el lado opuesto, enmarcando la imponente escultura de Jesús con San Juan. Esta arquitectura abierta recuerda la estampa de la Presentación de la Virgen al Templo de Alberto Durero en la serie de la Vida de la Virgen, y los modelos pintados por Alejo Fernández (h. 1470-Sevilla, 1545) en varias obras de su etapa cordobesa: Anunciación del Museo de Bellas Artes de Sevilla ( ${ }^{\circ}$ R. CR0044P), Cristo atado a la columna del Museo de Bellas Artes de Córdoba ( ${ }^{\circ}$ R. CE2128P) o la Flagelación del Museo del Prado (P001925). Los procedimientos técnicos empleados para conseguir las texturas del fieltro de los bonetes, diferenciar la caída de los paños y tocados, los elementos aplicados para decorar los cofres de los mercaderes, la mesa de los cambistas tratada en perspectiva, el junco de la cesta con palomas, la piel de los toros o la lana de las ovejas tuvieron una terminación cromática; el "blanquevol" abonado al pintor Diego de la Barrera que sellaría los poros del barro, avivaría la escena y remarcaría las calidades plásticas de los mercaderes, sacerdotes y jóvenes modelados en altorrelieve con sus cabezas sobresalientes en bulto redondo 25 (Figuras 5 y 7 ).

El movimiento libre y planos de la Expulsión de los mercaderes debieron influir decisivamente al encargar el tercer relieve para esta catedral, dos meses después de cerrar administrativamente los pagos por esta obra tan significativa. El 3 de noviembre de 1521 el cabildo efectuó el primer pago, a cuenta, de la "entrada de Nuestro Señor en Jerusalén el domingo de ramos", sin que conste quién realizó el dibujo o aportó el modelo preliminar donde Miguel Perrin desarrolló in extenso el mismo tratamiento escultórico ajustando la escena a la limitación impuesta por

24 ÁVILA PADRÓN, Ana: Imágenes y símbolos..., op. cit., pp. 13-45.

${ }^{25}$ HUIDOBRO, Concha: Grabados alemanes de la Biblioteca Nacional. Madrid, 1997, n 411 y 424; CIRUJANO, Concha y LAGUNA, Teresa: "Aproximación técnica a....”, op. cit., pp. 33-50; y CIRUJANO, Concha y LAGUNA, Teresa: "Ôeuvre et technique....", op. cit. pp. 150-165. 
el tímpano tardogótico, al que consiguió dar mayor profundidad. Combinó con maestría el modelado de las planchas y las colombinas de barro desde el alto relieve casi exento de algunos personajes de la zona exterior al volumen medio de los representados en el segundo plano, cerrado por edificios con ventanas y azoteas meridionales animadas por personajes que despliegan una idealizada ciudad de Jerusalén en bajo relieve.

Aquí el modelado es más complejo que en el tímpano de la puerta de los $\mathrm{Pa}$ los y el paisaje no es un telón escénico, meramente anclado a la pared del fondo, sino que está ligado a las figuras del segundo plano, desarrollándose gradual y unitariamente desde el interior hacia la superficie. En la secuencia técnica maestre Miguel comenzó el relieve modelando las planchas de la arquitectura a las que luego añadió sus cornisas y azoteas, los perfiles de las ventanas con sus moradores asomados y los que avivan la puerta de la muralla de esta Jerusalén donde situó siete personajes. Cuatro de estos con sus cabezas completamente moldeadas y tres con sus tocados desarrollados en volumen dan profundidad a los israelitas del segundo plano en medio relieve con sus cabezas de bulto redondo, a los apóstoles del extremo opuesto y a los niños de la capilla musical que participan simbólicamente de la acción en el centro del tímpano. Las copas de los árboles y la palmera con Zaqueo, realizadas con piezas recortadas y rulos de barro de distinto grosor, destacan sobre las cabezas de los apóstoles. Delante de estos grupos el altorrelieve del Salvador sobre la borriquita y la figura del segundo hebreo que le tiende la túnica, cuyos cuerpos terminan exentos, forman el primer plano de la acción, completada por las tres esculturas de bulto redondo: San Pedro, cuyo codo izquierdo penetra en el lomo del borrico, el judío arrodillado con el manto y el posterior en actitud de reverencia al Mesías. En esta zona el modelado de cada personaje es individual y para que parezcan figuras completas hizo sus torsos, cabezas y brazos en bulto redondo, vació la parte posterior del judío y de la borriquita para adherirlas al fondo y dejó los huecos necesarios para insertar posteriormente las piezas de las manos, del pie del Señor o las patas exteriores del animal fijadas con pasadores de madera. Las uniones de los cortes de cocción, magníficamente maridados, y algunos elementos decorativos de los tocados que ocultan los orificios evitaron la condensación de vapor de agua durante la cocción; su forma o posición varía en función de cada zona del relieve, testimoniándonos la calidad técnica de este imaginero; manifiestan su amplia formación y el bagaje artístico que le trajo a Sevilla a finales de $1517^{26}$ (Figuras 6 y 8).

Este procedimiento de modelado invierte el proceso de talla en los relieves de madera, piedra, alabastro o marfil realizado desde la superficie hasta los planos del fondo, consiguiendo los mismos efectos de profundidad y espacios vacíos

${ }^{26}$ CIRUJANO, Concha y LAGUNA PAÚL, Teresa: "Aproximación técnica a las esculturas...", op. cit., pp. 35-44; y CIRUJANO, Concha y LAGUNA, Teresa: "Ôeuvre et technique de Miguel Perrin....", op. cit., pp. 158-165. 
entre los personajes. Con este método acentuaron la perspectiva y la profundidad en relieves modelados en barro cocido de mediano formato como, por ejemplo, en las piezas del martirio de santos franciscanos del púlpito de la iglesia de Santa Croce de Florencia, realizadas por Benetto da Maiano hacia 1480 (Victoria \& Albert, Inv. 240/242-1889). No obstante, los relieves monumentales de este tímpano de $253 \mathrm{~cm}$ de alto y $325 \mathrm{~cm}$ de largo máximo, cuyos personajes del primer plano alcanzan aproximadamente $130 \mathrm{~cm}$ de altura, requieren procedimientos equiparables a los desarrollados por los artistas del Piamonte, de la Lombardía, de la Emilia Romagna o de la Toscana desde finales del siglo XV analizados técnicamente en la restauración del Compianto del altar de la capilla funeraria de Pandolfo Petrucci, en la sacristía del convento de San Bernardino della Osservancia en Siena, realizado por Giacomo Cozzarelli en $1498^{27}$.

Miguel Perrin debía conocer estos métodos o colaborado en algún taller especializado en ellos, pero desconocemos si los desarrolló in extenso antes de estos encargos o corresponderían a su etapa de madurez sevillana. Las características técnicas y calidad de todos ellos determinaría otros encargos particulares y su tipología aparece expresamente definida en el contrato del altar de la Lamentación de la capilla de Antonio Imperial en Santiago de Compostela al indicar "ocho ymájenes de bulto de barro cocido de siete palmos de alto cada una, poco más o menos, e se entienda que han de ser las ymagenes que puedan paresçer del todo enteras"; sintetiza su trayectoria y cultura visual ${ }^{28}$. No obstante, en estos relieves de la catedral hispalense, Miguel Perrin continuó moldeando los mismos tipos y modelos del primer renacimiento aprendido y desarrollado, también, por los imagineros franceses del 1500, mientras que las terracotas italianas de Giacomo Cozzarelli (Siena, 1453-1515), Guido Mazoni (Módena, 1450 -1518), Antonio Begarelli (Módena, 1499-1565) o de Tullio Lombardo (Padua 1455/1460-Venecia 1532) tienen improntas estéticas más evolucionadas, incluso manieristas ${ }^{29}$.

Los relieves de la catedral de Sevilla y el altar compostelano evidencian la formación, la cultura visual y la evolución profesional de Miguel Perrin, así como las transferencias artísticas entre las cortes y reinos europeos en la recepción del modelo italiano y la formulación definitiva del Renacimiento en los diversos territorios de la península Ibérica. Cuando llegó a Sevilla en noviembre de 1517 fue el escultor que, después de la muerte de Pedro Millán (1509), renovó la escultura en barro cocido en esta ciudad durante el primer tercio del siglo XVI antes de la

${ }^{27}$ GIUSTI, Anna Maria (coord.): Restauro di una terracotta del Quattrocento. Il 'Compianto’ di Giacomo Cozzarelli. Módena, 1984.

${ }^{28}$ HERNÁNDEZ DÍAZ, José: "Una obra de maestre Miguel...”, op. cit., p. 150; y LAGUNA PAÚL, Teresa: "De Sevilla a Santiago de Compostela. Miguel Perrin y el altar de la capilla de la Piedad de la catedral compostelana", Artigrama, 33, 2018, pp. 161-186.

${ }^{29}$ BONSANTI, Giorgio y PICCINI, Francesca: Emozioni in terracotta. Guido MazzonilAntonio Begarelli. Scultore del Rinascimiento emiliano. Módena, 2009. 
llegada de Pietro Torrigiano (h. 1522-1528) y de los manieristas de la segunda mitad de esta centuria. Sus modelos, su técnica, su cultura visual y sus fuentes figurativas corresponden a los de una generación puente que superó a través de Italia el modelo nórdico y el realismo borgoñón contribuyendo decisivamente en la aceptación plena del lenguaje renacentista.

Fecha de recepción: 30 de octubre de 2018

Fecha de aceptación: 5 de febrero de 2019 


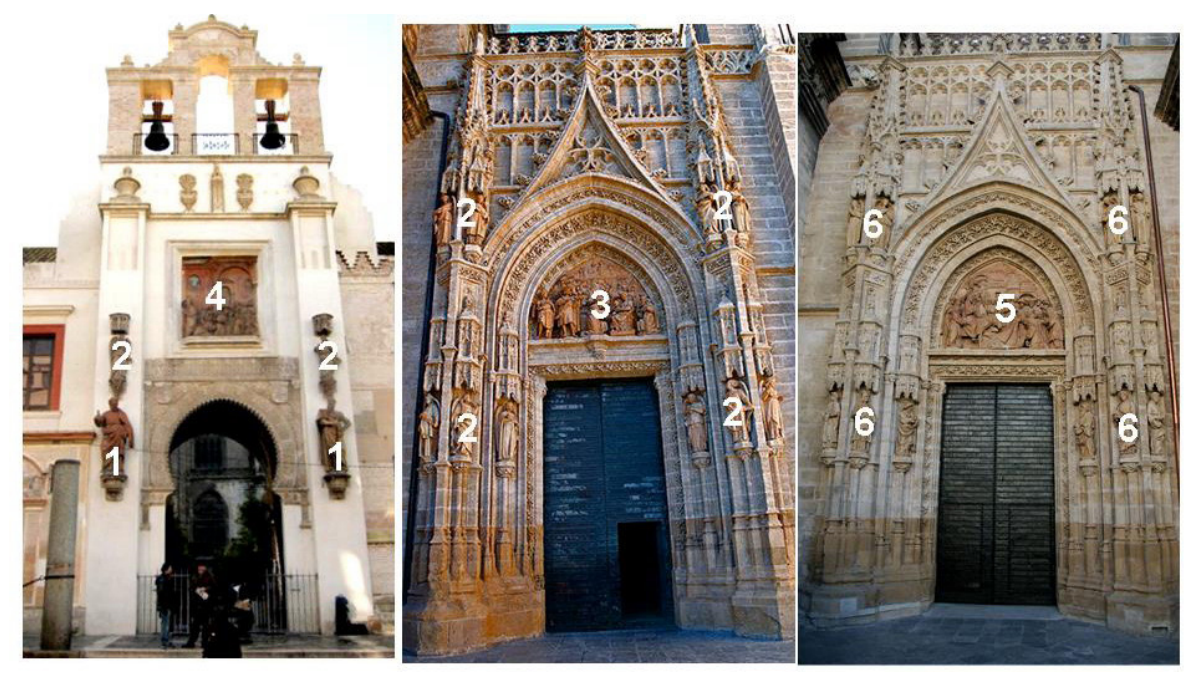

Figura 1. Secuencia de los contratos y trabajos escultóricos de Miguel Perrin en las portadas del Perdón "vieja", Adoración de los Reyes (Palos) y Entrada en Jerusalén (Campanilla) entre 1519 y 1523, catedral de Sevilla. Foto: Teresa Laguna Paúl.

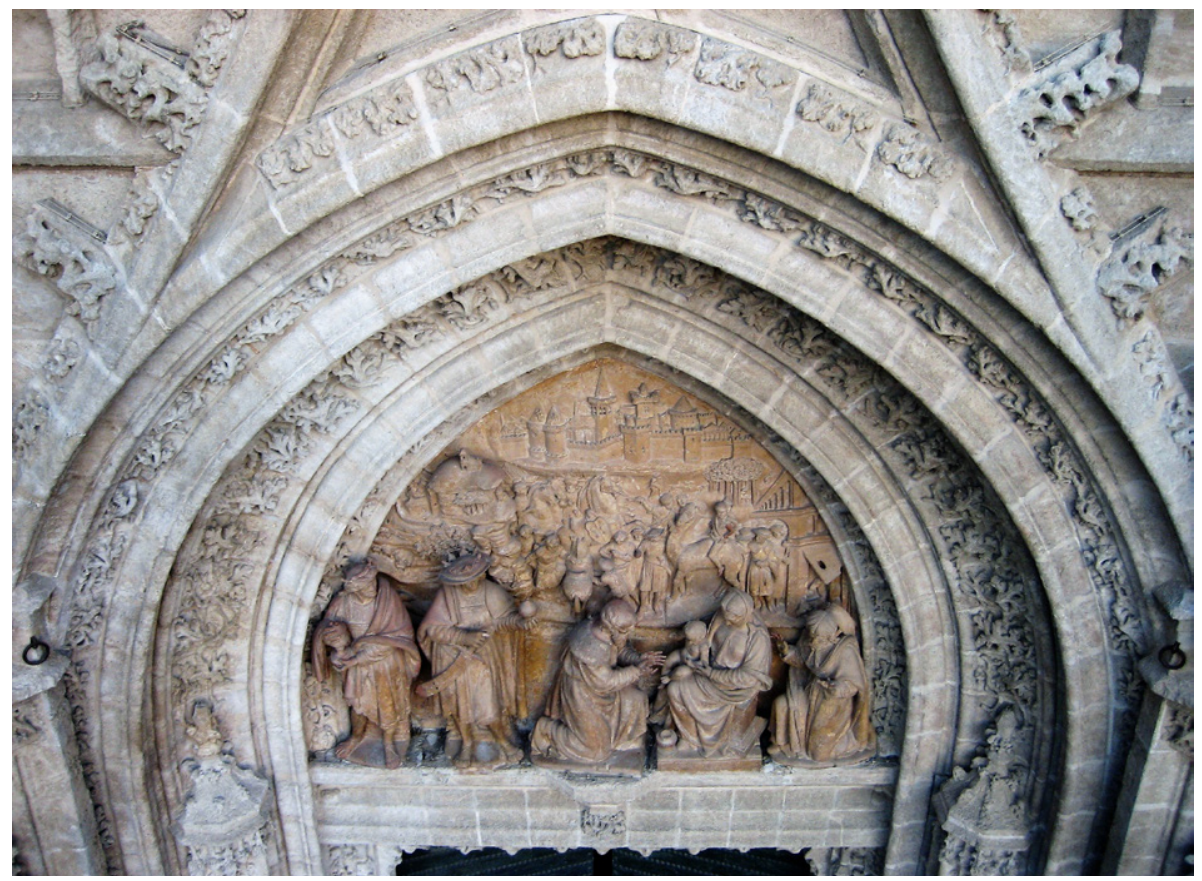

Figura 2. Miguel Perrin, Relieve y esculturas del tímpano de la Adoración de los Reyes, 1520, catedral de Sevilla. Foto: Teresa Laguna Paúl. 
Figura 3. Anónimo francés del primer tercio del siglo XVI, Rey Melchor, barro cocido, donado en 1864 por el abad Cordier a la iglesia de Notre-Dame de Pontoise. Foto: Teresa Laguna Paúl.
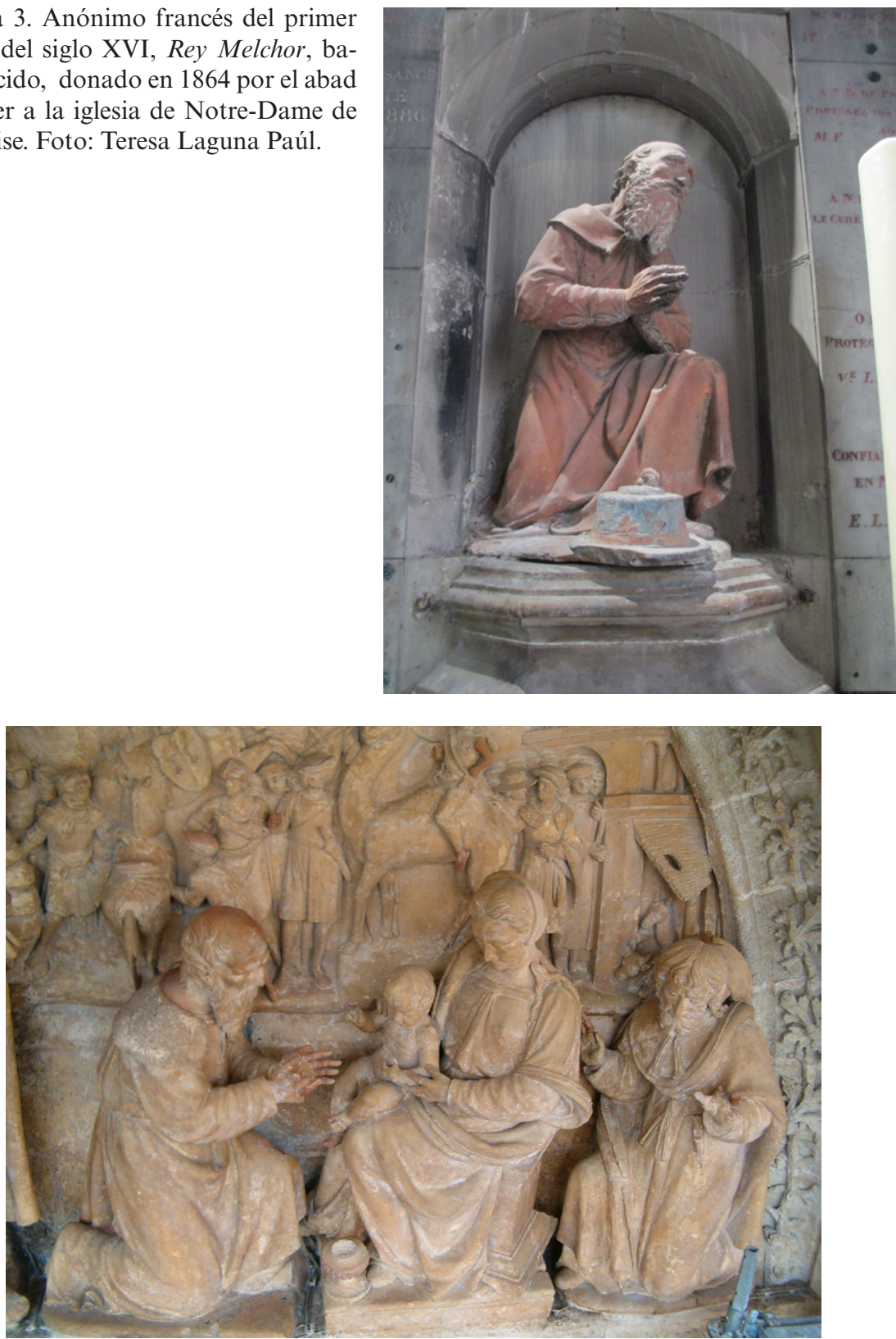

Figura 4. Miguel Perrin, Detalle de la cabalgata del tímpano de la Adoración de los Reyes, 1520, puerta de los Palos de la catedral de Sevilla. Foto: Teresa Laguna Paúl. 

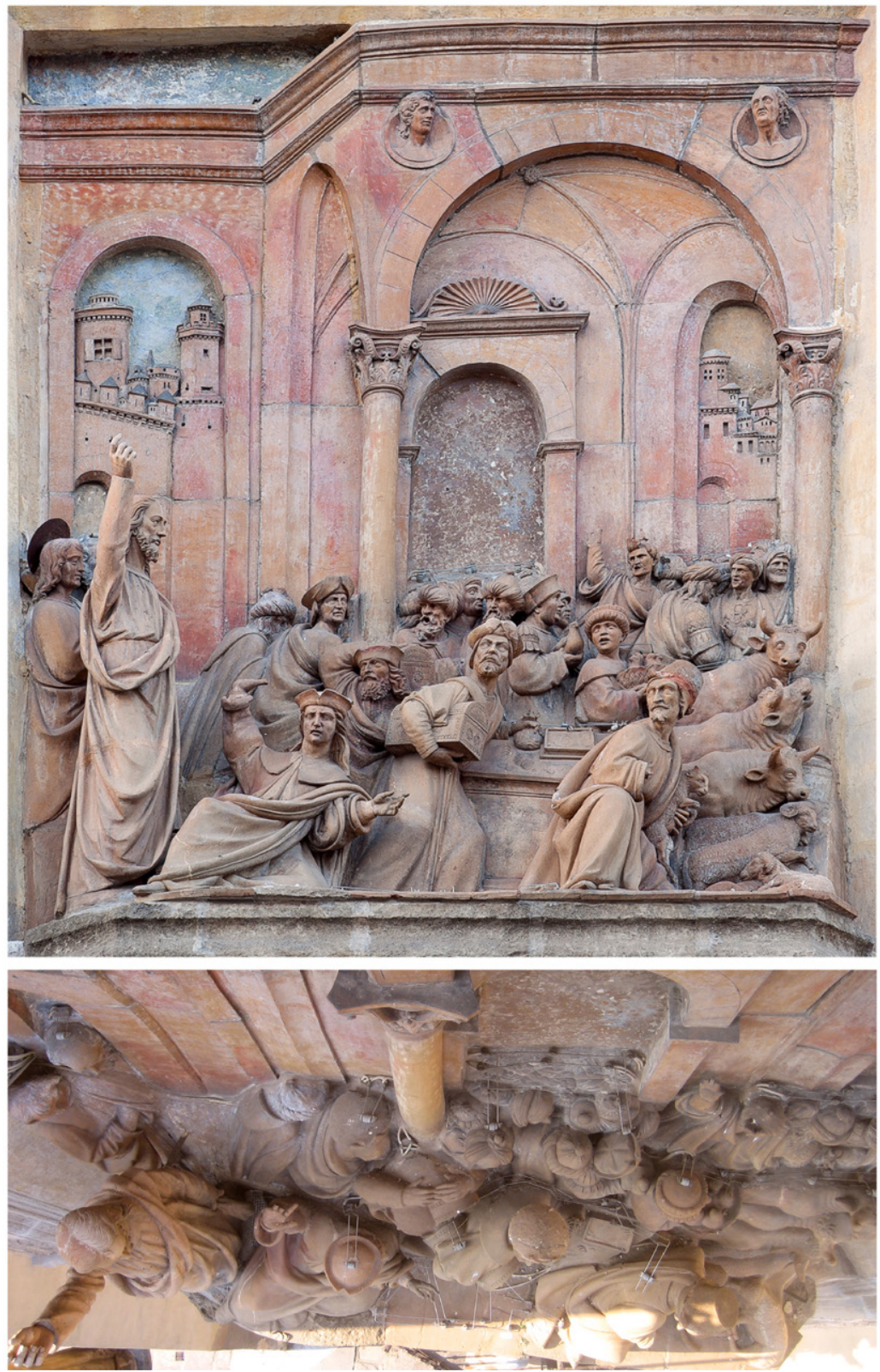

Figura 5. Miguel Perrin, Expulsión de los mercaderes del templo de la puerta del Perdón "vieja" de la catedral de Sevilla, 1520-1521. Foto: Teresa Laguna Paúl. 

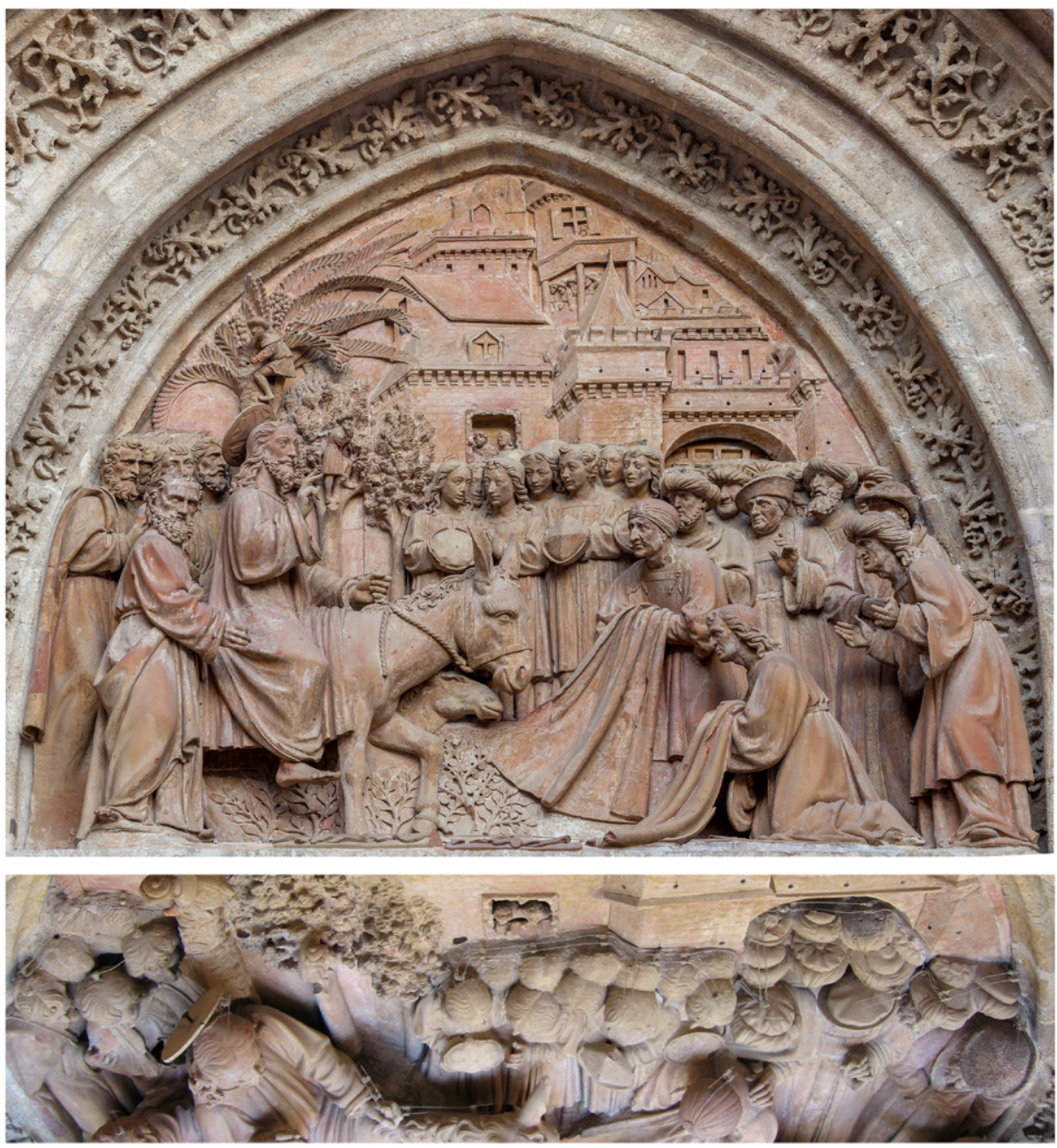

Figura 6. Miguel Perrin, Tímpano de la Entrada en Jerusalén con las huellas de los cortes de cocción y planos del relieve, 1521-1522. Foto: Teresa Laguna Paúl. 

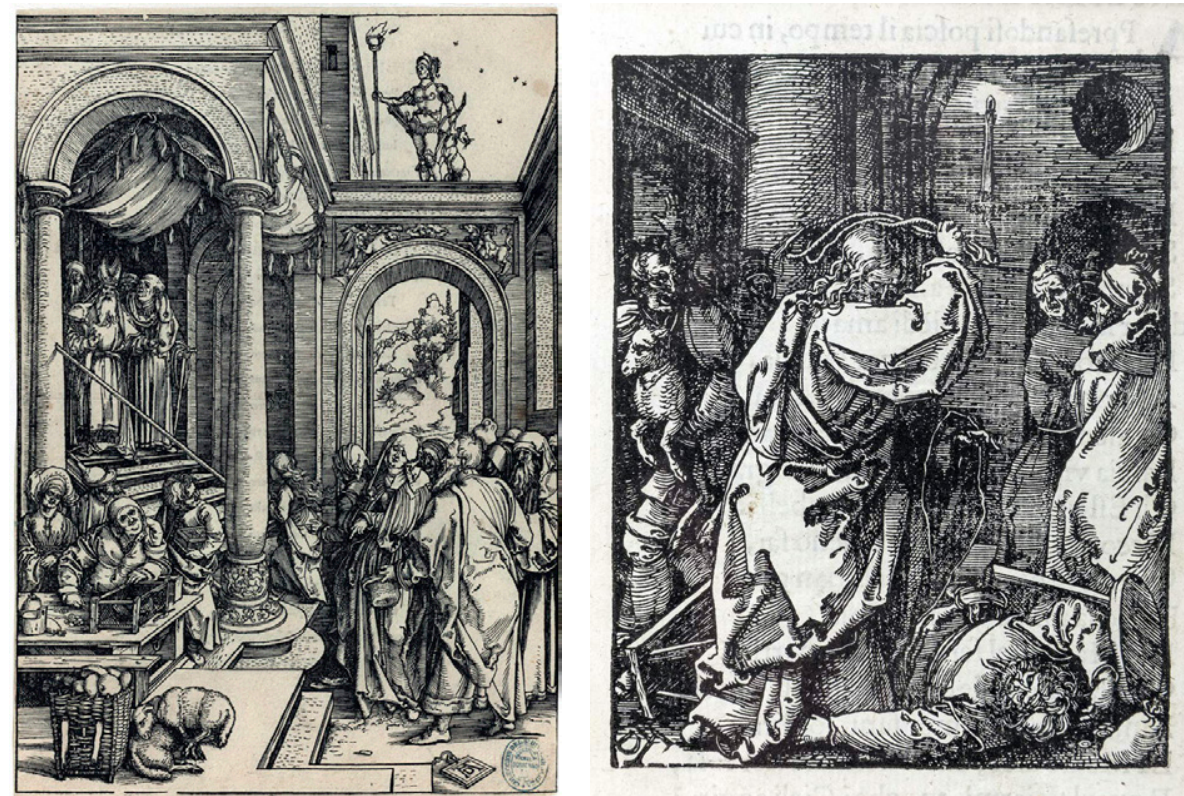

Figura 7. Alberto Durero, Presentación de la Virgen al Templo y Cristo expulsando a los mercaderes del templo, Biblioteca Nacional de España, Madrid.

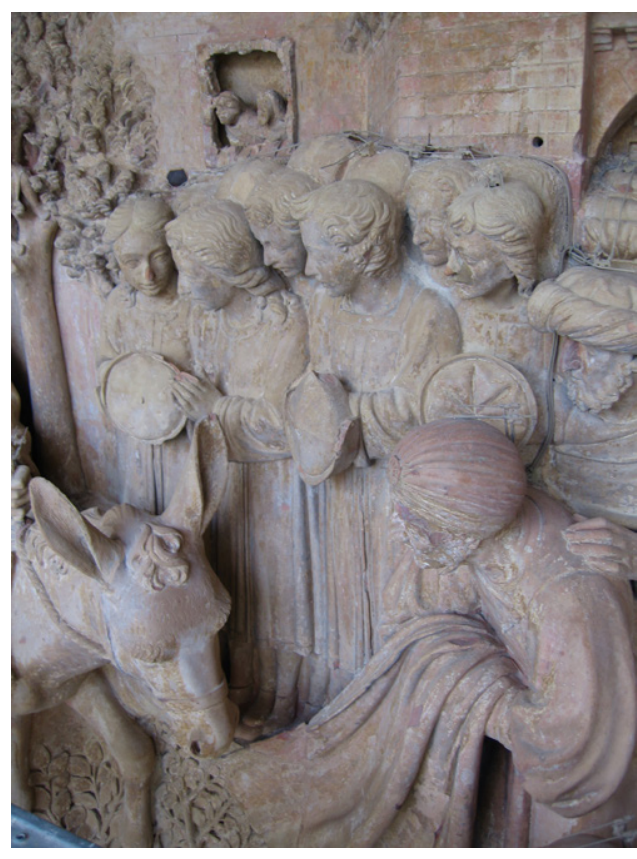

Figura 8. Miguel Perrin, Pormenor del altorrelieve de la entrada en Jerusalén, puerta de la Campanilla de la catedral de Sevilla. Foto: Teresa Laguna Paúl. 